\title{
Effect of hepatitis C virus infection on erythropoiesis in patients on hemodialysis
}

This article was published in the following Dove Press journal: International Journal of Nephrology and Renovascular Disease 27 June 2013

Number of times this article has been viewed

\section{Chadi Saifan \\ Elie El-Charabaty \\ Morton Kleiner \\ Suzanne El-Sayegh}

Department of Medicine, Division of Nephrology, Staten Island University Hospital, Staten Island, NY, USA
Correspondence: Chadi Saifan

Department of Medicine, Division of Nephrology, Staten Island University Hospital, Staten Island, NY, USA

Tel +l 7182269000

Fax +17182266466

Email chadisaifan@hotmail.com
Background: Erythropoietin is a hormone that regulates erythropoiesis and is mainly produced by the kidneys. Several animal studies as well as a few case reports and case series have demonstrated that regenerating hepatic tissue can produce more erythropoietin than normal hepatic tissue. The purpose of the study was to examine the difference in hemoglobin and hematocrit levels as well as epoetin dosage in patients on hemodialysis with and without hepatitis $\mathrm{C}(\mathrm{HCV})$.

Methods: A retrospective chart review was performed. Seventy-six patients were included in the study (19 with $\mathrm{HCV}$ and 57 without $\mathrm{HCV}$ ) at a ratio of 1:3. Exclusion criteria were a history of gastrointestinal bleeding or blood transfusion over the previous six months, polycystic kidney disease, and pregnancy. Variables examined included gender, age, duration of hemodialysis, hemoglobin, hematocrit, epoetin dose, aspartate transaminase, and ferritin levels over a threemonth period.

Results: The patients were divided into two groups. The first consisted of patients with HCV on hemodialysis and the second of patients on hemodialysis without HCV. Mean hemoglobin was $12.6 \pm 1.2 \mathrm{~g} / \mathrm{dL}$ for the HCV-positive group and $11.9 \pm 1.1 \mathrm{~g} / \mathrm{dL}$ for the HCV-negative group. The difference was statistically significant $(P=0.03)$. Mean hematocrit was higher in the HCVpositive group, but was not significantly different at $39.08 \% \pm 4.06 \%$ versus $37.43 \% \pm 3.4 \%$ in the HCV-negative group ( $t$-test, $P=0.11$ ). Further, the HCV-positive group required less epoetin, but this was not significantly different from that required in the HCV-negative group at $6258 \pm 5208 \mathrm{IU}$ versus $7596 \pm 7056 \mathrm{IU}$, respectively $(t$-test, $P=0.38)$.

Conclusion: In our study, patients with HCV infection were found to have higher hemoglobin and hematocrit levels and lower epoetin requirements than those without HCV. Although the findings were not statistically significant, the computed values between these two groups of patients did follow a general trend. Further investigation with more patients, a longer duration of follow-up, and incorporation of additional medical variables is needed to clarify the role of $\mathrm{HCV}$ on erythropoiesis in hemodialysis patients.

Keywords: hepatitis C virus, erythropoiesis, hemodialysis, hematocrit, epoetin

\section{Introduction}

In recent years, many advances have been made in the treatment of chronic kidney disease. Anemia is a frequent complication of chronic renal failure. The association of anemia with increased cardiovascular morbidity and mortality and decreased quality of life in patients with end-stage renal disease is well recognized. Erythropoietin, which is mainly produced by the kidneys, is a glycoprotein hormone that regulates red blood cell production or erythropoiesis. The high incidence of anemia in chronic kidney disease is due predominantly to inadequate production of erythropoietin from 
failing kidneys. With the development of recombinant human erythropoietin (rHuEpo) in 1989, renal anemia can be treated effectively. Replacement of erythropoietin with rHuEpo can increase red blood cell mass and reduce the need for blood transfusions. ${ }^{1,2}$

More than 30 years ago, Jacobson et al established that the kidney is the major organ of erythropoietin production in adult rats. ${ }^{3}$ The recent cloning of the murine erythropoietin gene has allowed studies on the production of erythropoietinspecific mRNA in anemic mice. Within one hour, induction of anemia leads to the appearance of erythropoietin-encoding mRNA in the kidney and liver of mice and rats. ${ }^{3,4}$ After bleeding, the erythropoietin mRNA in the kidney increases to 500-1000 times that of normal, whereas the liver produces only $7 \%$ of total erythropoietin mRNA. ${ }^{4}$ In no tissue other than the kidneys and liver is erythropoietin mRNA detectable, even in the presence of anemia. ${ }^{4}$ During fetal life, hepatic production of erythropoietin is of major importance for red blood cell production. Anephric fetal sheep and anephric neonatal rats produce normal amounts of erythropoietin and red cells..$^{5}$ At the time of birth, there is a gradual and irreversible switch from hepatic to renal production. ${ }^{6}$ Of interest, however, is the fact that regenerating hepatic tissue, such as that found in rats after partial hepatectomy, synthesizes more erythropoietin than does normal adult hepatic tissue.

In addition to animal studies, several case reports in human subjects have been published in the literature relating polycythemia to hepatitis in patients with and without renal failure. Giovanardi et al reported a case of erythrocytosis in a patient with hepatocellular carcinoma and alcoholic cirrhosis with ectopic production of erythropoietin. ${ }^{7}$ In addition, Klassen et al reported a 28 -year-old transfusiondependent male on hemodialysis who developed hepatitis with a concomitant increase in hemoglobin and hematocrit as well as erythropoietin level. ${ }^{5}$ Simon et al reported a 45 -yearold woman who had undergone bilateral nephrectomy and was subsequently hemodialysis-dependent. The patient developed non-A non-B cytolytic hepatitis with spontaneous improvement of her anemia and an elevated erythropoietin level two months after onset of her hepatitis. During the following months, her hepatic cytolysis and polycythemia subsided and her erythropoietin level decreased. ${ }^{7}$ A case series of four patients with hepatitis B followed for three months to compare their response to epoetin and endogenous erythropoietin levels with those of a control group of patients without hepatitis B virus (HBV) infection concluded that patients with HBV surface antigen have much higher levels of endogenous erythropoietin and require fewer exogenous erythropoietin injections that their counterparts. ${ }^{4}$ Radovic et al demonstrated that red blood cell production increases as a result of elevated circulating erythropoietin during hepatic regeneration after $\mathrm{HBV}$ or $\mathrm{HCV}$ infection. ${ }^{6}$

Chronic HCV infection is common in hemodialysis patients, and is the most common cause of acute and chronic hepatitis in this population. After review of these data, we ask, "Do patients on hemodialysis with HCV infection have greater hepatic erythropoietin production and subsequently higher hemoglobin and hematocrit levels than their HCVnegative counterparts?"

This study examines the difference in hemoglobin and hematocrit levels between patients on hemodialysis with a diagnosis of HCV and a group of patients on hemodialysis without HCV. Further, the study compares the difference in erythropoietin dose required in patients on hemodialysis who are anti-HCV positive and that required in those on hemodialysis who are anti-HCV negative. The aim of the study was to define the influence of HCV infection on erythropoiesis in hemodialysis patients.

\section{Materials and methods}

The institutional review board at Staten Island University Hospital approved the protocol of this study. The study population consisted of patients on hemodialysis at the Staten Island Rehabilitation Center in Staten Island and Island Rehabilitative Services Dialysis Facility in Brooklyn, NY, USA. A retrospective chart review was undertaken for 76 patients with end-stage renal disease on hemodialysis. Of these 76 patients, 19 had a diagnosis of HCV confirmed by anti-HCV positivity. The remaining 57 patients were anti$\mathrm{HCV}$ negative and were included as an age-matched control group. This method of patient selection yielded a 1:3 ratio of anti-HCV positive to anti-HCV negative patients. Variables examined in this review included age, gender, duration of hemodialysis, hemoglobin, hematocrit, epoetin dose per treatment, and aspartate transaminase and ferritin levels. Exclusion criteria were a previous history of gastrointestinal bleeding or blood transfusion in the previous six months, history of polycystic kidney disease, and pregnancy.

The patients were divided into two groups. Group 1 consisted of patients on hemodialysis with a history of $\mathrm{HCV}$ documented by a positive antibody to HCV. Group 2 consisted of patients on hemodialysis without $\mathrm{HCV}$ as documented by negative antibodies to $\mathrm{HCV}$. Group 2 patients served as age-matched and gender-matched controls for the patients in Group 1. Group differences were examined using the $t$-test. 
The NCSS statistical package version 2004 was used for all analyses. The results were shown as the mean \pm standard deviation. A $P$ value $<0.05$ was considered to be statistically significant.

\section{Results}

The study population consisted of 76 patients (19 anti-HCV antibody-positive and 57 anti-HCV antibody-negative) divided into two groups. The first group consisted of patients with HCV on hemodialysis (11 men, eight women), and the second group consisted of patients without HCV on hemodialysis (37 men, 20 women). Demographic features and laboratory parameters are shown in Table 1 .

The mean age was $59.45 \pm 14.8$ years in the anti-HCVpositive group and $58.84 \pm 12.2$ years in the anti-HCVnegative group. The $t$-test revealed no significant difference in age between the control group and the HCV group. The mean duration of time of hemodialysis was significantly longer in the anti-HCV-positive group $(8.64 \pm 6.56$ years $)$ than in the anti-HCV-negative group ( $4.80 \pm 4.80$ years). This difference was statistically significant $(P=0.01)$. The HCVpositive group had a higher mean aspartate transaminase value $(33.95 \pm 33.5 \mathrm{IU} / \mathrm{mL})$ than the $\mathrm{HCV}$-negative group $(18.50 \pm 10.1 \mathrm{IU} / \mathrm{mL})$. This difference was statistically significant, $(P=0.001)$. The $\mathrm{HCV}$-positive group had lower ferritin levels at $538 \pm 340 \mathrm{ng} / \mathrm{mL}$ versus the negative group at $654 \pm 415 \mathrm{ng} / \mathrm{mL}$. However, the difference was not statistically significant $(P=0.22)$.

Mean hemoglobin over three months was $12.6 \pm 1.2 \mathrm{~g} / \mathrm{dL}$ for the HCV-positive group and $11.9 \pm 1.1 \mathrm{~g} / \mathrm{dL}$ for the HCVnegative group. This difference was statistically significant $(P=0.03)$. Mean hematocrit was higher in the HCV-positive group, but was not significantly different at $39.08 \% \pm 4.06 \%$ versus $37.43 \% \pm 3.4 \%$ in the $\mathrm{HCV}$-negative group $(P=0.11)$.

Table I Demographic and laboratory parameters in anti-HCV positive and anti-HCV-negative patient groups

\begin{tabular}{llll}
\hline $\begin{array}{l}\text { Demographic and } \\
\text { laboratory parameters }\end{array}$ & $\begin{array}{l}\text { HCV- } \\
\text { positive }\end{array}$ & $\begin{array}{l}\text { HCV- } \\
\text { negative }\end{array}$ & P value \\
\hline Gender (M/F) & \multicolumn{1}{l}{$\mathrm{I} / 8$} & $37 / 20$ & - \\
Age (years) & $59.45 \pm 14.8$ & $58.84 \pm 12.2$ & NS (0.85) \\
Duration of HD (years) & $8.64 \pm 6.56$ & $4.80 \pm 4.80$ & $0.0 \mathrm{I}$ \\
Ferritin (ng/mL) & $538 \pm 340$ & $654 \pm 415$ & $\mathrm{NS}(0.22)$ \\
AST (IU/mL) & $33.95 \pm 33.5$ & $18.50 \pm 10.1$ & $0.00 \mathrm{I}$ \\
Mean epoetin dose (IU) & $6258 \pm 5208$ & $7596 \pm 7056$ & $\mathrm{NS}(0.38)$ \\
Hemoglobin (g/dL) & $12.6 \pm 1.2$ & $11.9 \pm 1.1$ & 0.03 \\
Hematocrit $(\%)$ & $39.08 \pm 4.06$ & $37.43 \pm 3.40$ & $\mathrm{NS}(0.1 \mathrm{I})$ \\
\hline
\end{tabular}

Abbreviations: AST, aspartate transaminase; HCV, hepatitis C virus; HD, hemodialysis; NS, not statistically significant.
The average epoetin dose given over three months was also compared for both groups. The HCV-positive group required lower doses, but the difference was not significantly different from that required in the $\mathrm{HCV}$-negative group, at $6258 \pm 5208$ IU versus $7596 \pm 7056 \mathrm{IU}$, respectively $(P=0.38)$.

\section{Discussion}

$\mathrm{HCV}$ infection causes significant morbidity and mortality in patients with end-stage renal disease on hemodialysis. The prevalence of anti-HCV antibody is higher in patients on hemodialysis than in healthy populations. Several risk factors contributing to this high prevalence of $\mathrm{HCV}$ infection have been identified, and include the number of blood transfusions, duration of end-stage renal disease, mode of dialysis, and prevalence of $\mathrm{HCV}$ infection in the dialysis unit. ${ }^{9}$

Several case reports and studies have linked hepatic regeneration secondary to viral or toxic injury with increased red cell production in patients with and without chronic renal failure. Recently, Sahin et al found that anti-HCV-positive patients with end-stage renal disease had higher hemoglobin and hematocrit levels than anti-HCV-negative patients. ${ }^{10}$ Similarly, Altintepe et al concluded that anti-HCV positive patients on hemodialysis had higher serum erythropoietin levels and required less exogenous erythropoietin and iron than anti-HCV-negative patients. ${ }^{11}$ However, the effect of $\mathrm{HCV}$ infection on erythropoiesis has still not been fully elucidated. The aim of our study was to define further the effect of $\mathrm{HCV}$ infection on erythropoiesis in patients with end-stage renal disease through our patient population.

It has been reported that the duration of hemodialysis is significantly longer in anti-HCV-positive patients than in anti-HCV-negative patients. Further, it has been observed that patients on hemodialysis for more than 10 years have an increased incidence of $\mathrm{HCV}$ infection. The risk of acquiring $\mathrm{HCV}$ infection on hemodialysis is estimated at approximately $10 \%$ per year. ${ }^{9}$ In our study, we also observed that patients with $\mathrm{HCV}$ infection spent a significantly longer time on hemodialysis that those without HCV infection. In addition, we observed the HCV-infected group to have a higher mean aspartate transaminase level than the control group, reflecting the expected increase in transaminase levels secondary to hepatic injury.

In our study, hemodialysis patients with $\mathrm{HCV}$ infection tended to have higher mean hemoglobin and hematocrit levels than those without HCV infection. We also observed that the average dose of epoetin required was lower in the anti-HCVpositive group than in the anti-HCV-negative group. Although the differences in hematocrit and epoetin dosage were not 
statistically significant, the mean values did follow a general trend which is in agreement with past reports of increased hemoglobin and hematocrit and decreased erythropoietin requirements in patients with liver injury. Our findings may reflect increased endogenous erythropoietin production by regenerating hepatocytes. It is well known that high hemoglobin levels $>12 \mathrm{mg} / \mathrm{dL}$ are linked with an increased risk of stroke and cardiovascular events. ${ }^{12}$

The small sample size of HCV-infected patients and short three-month period of follow-up were the limitations of this study. A prospective trial including more patients from more hemodialysis centers is needed. Another limiting factor is that endogenous erythropoietin levels were not directly measured. Additional clinical variables, such as parathyroid hormone levels, transferring saturation, human immunodeficiency virus status, and presence of chronic infections and other comorbidities, should be incorporated into future studies because these variables affect responsiveness to erythropoietin therapy. Further, the primary etiology of renal failure for each individual patient should be taken into account, because different forms of renal failure cause varying degrees of erythropoietin deficiency. In conclusion, we believe that further investigation is needed to clarify the role of $\mathrm{HCV}$ on erythropoiesis in patients on hemodialysis.

\section{Disclosure}

The authors report no conflicts of interest in this work.

\section{References}

1. Locatelli F, Pisoni RL, Akizawa T, et al. Anemia management for hemodialysis patients: Kidney Disease Outcomes Quality Initiative (K/DOQI) guidelines and Dialysis Outcomes and Practice Patterns Study (DOPPS) findings. Am J Kidney Dis. 2004;44(5 Suppl 2):27-33.

2. Mahajan S, Boulton H, Gokal R. A trial of subcutaneous administration of darbepoetin alfa once every other week for the treatment of anemia in peritoneal dialysis patients. $J$ Nephrol. 2004;17(5):687-692.

3. Jacobson LO. From atom to eve. Perspect Biol Med. 1981;24(2): 195-216.

4. Ifudu O, Fowler A. Hepatitis B virus infection and the response to erythropoietin in end-stage renal disease. ASAIO J. 2001;47(5):569-572.

5. Klassen DK, Spivak JL. Hepatitis-related hepatic erythropoietin production. Am J Med. 1990;89(5):684-686.

6. Radovic M, Jelkmann W, Djukanovic L, Ostric V. Serum erythropoietin and interleukin-6 levels in hemodialysis patients with hepatitis virus infection. J Interferon Cytokine Res. 1999;19(4):369-373.

7. Simon P, Boffa G, Ang KS, Menault M. Polycythaemia in a haemodialyzed anephric patient with hepatitis. Demonstration of erythropoietin secretion. Nouv Presse Med. 1982;11(18):1401-1403. French.

8. Giovanardi P, Sacchetti C, Cameroni P, Grandi M. Erythrocytosis in patients with hepatocarcinoma in alcoholic cirrhosis: ectopic production of erythropoietin?. Recenti Prog Med. 1998;89(5):250-252. Italian.

9. Natov SN, Lau JY, Bouthot BA, et al. Serologic and virologic profiles of hepatitis $\mathrm{C}$ infection in renal transplant candidates. New England Organ Bank Hepatitis C Study Group. Am J Kidney Dis. 1998;31(6): 920-927.

10. Sahin I, Arabaci F, Sahin HA, et al. Does hepatitis C virus infection increase hematocrit and hemoglobin levels in hemodialyzed patients? Clin Nephrol. 2003;60(6):401-404.

11. Altintepe L, Kurtoglu E, Tonbul Z, Yeksan M, Yildiz A, Türk S. Lower erythropoietin and iron supplementation are required in hemodialysis patients with hepatitis C virus infection. Clin Nephrol. 2004;61(5): 347-351.

12. Fujikawa T, Ideda Y, Fukuhara S, Akizawa T, Kurokawa K, Saito A. Time-dependent resistance to erythropoiesis-stimulating agent and mortality in hemodialysis patients in the Japan dialysis outcomes and practice patterns study. Nephron Clin Pract. 2013;122(1-2):24-32.

\section{Publish your work in this journal}

The International Journal of Nephrology and Renovascular Disease is an international, peer-reviewed open-access journal focusing on the pathophysiology of the kidney and vascular supply. Epidemiology, screening, diagnosis, and treatment interventions are covered as well as basic science, biochemical and immunological studies. The journal welcomes original research, clinical studies, reviews \& evaluations, expert opinion and commentary, case reports and extended reports. The manuscript management system is completely online and includes a very quick and fair peerreview system, which is all easy to use. Visit http://www.dovepress.com/ testimonials.php to read real quotes from published authors. 